\title{
Publisher Correction: Difference in the Tailpipe Particle Number by Consideration of Sub-23-nm Particles for Different Injection Settings of a GDI Engine
}

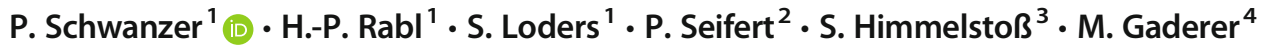

Published online: 13 March 2019

(C) Springer Nature Switzerland AG 2019

Publisher Correction: Emission Control Science and Technology https://doi.org/10.1007/s40825-019-0114-1

The original version of this article unfortunately contained a mistake. Figures 6,11 and 13 were not properly processed.

The original version has been corrected.

Publisher's Note Springer Nature remains neutral with regard to jurisdictional claims in published maps and institutional affiliations.

The online version of the original article can be found at https://doi.org/ 10.1007/s40825-019-0114-1

P. Schwanzer

peter.schwanzer@oth-regensburg.de

\section{P. Seifert}

seifert@scale-MT.de; https://scale-mt.de/

1 Ostbayerische Technische Hochschule Regensburg, Regensburg, Germany

2 Scale MT, Regensburg, Germany

3 Universität Regensburg, Regensburg, Germany

4 TUM Campus für Biotechnologie und Nachhaltigkeit Straubing, Straubing, Germany 